\title{
Planificación situacional aplicada al sector socioeconómico venezolano. Caso: "Emprendedores Emergentes de negocios"*
}

\author{
Alizo, María Alexandra** \\ Graterol, Angela*** \\ Añez, Silenis****

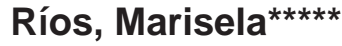

\section{Resumen}

El artículo tiene por objetivo presentar los resultados arrojados de la aplicación del modelo de Planificación de Situaciones (PES) al ámbito económico social venezolano, bajo la dinámica de las políticas que se dilucidaban durante el período de 2000. La metódica empleada en el análisis fue exploratoria, documental y descriptiva ya que la aplicación de este Modelo de Planificación Estratégica Situacional así lo requiere. El resultado de la investigación, luego de aplicar los instrumentos de análisis de los momentos explicativo, normativo y estratégico, indica que la alternativa de acción estratégica que promueve el cambio situacional para solventar el problema concreto seleccionado, el desempleo, es la del proyecto de Fomento y Apoyo a los Emprendedores Emergentes de Negocios al generar un mayor efecto dinamizador en la economía. Como estrategias de carácter procesal se exhortó

\section{Recibido: 05-11-03. Aceptado: 06-07-26}

* Este artículo contiene resultados de una investigación preliminar soporte del proyecto de investigación en desarrollo intitulado: "Análisis de la Gestión Económica - Financiera de los Emprendedores Emergentes de Negocios en el Municipio Maracaibo, Edo. Zulia. Período 1998-2003”, adscrito al Centro de Investigaciones Económicas y Sociales de la Facultad de Ciencias Económicas y Sociales (FCES) de la Universidad del Zulia (LUZ). Proyecto financiado por el Consejo de Desarrollo Científico y Humanístico de LUZ (CONDES).

** MgSc en Gerencia de Empresas. Investigador. Profesor FCES/LUZ. E-mail: marialexa110@yahoo.com, marialexa4@cantv.net, marialexa4@hotmail.com y malizo@luz.edu.ve.

*** MgSc en Finanzas y Macroeconomía. Investigador - Profesor FCES/LUZ.

E-mail: agraterol@hotmail.com y agraterol60@yahoo.com.

**** Doctora en Ciencias, mención Gerencia. MgSc. en Gerencia de Empresas y en Derecho del Trabajo. Profesor - Investigador FCES/LUZ. E-mail: sañez@luz.edu.ve.

***** Economista, analista de la DPGU de LUZ.

E-mail: maricruse@yahoo.com y mariselarios24@hotmail.com. 
la aplicación de mesas de diálogo, concertación y alianzas estratégicas (cooperación y cooptación) que generarán el clima político apropiado para favorecer la adecuada aplicación del proyecto.

Palabras clave: Planificación, situación, estrategia, política, desempleo y emprendedores emergentes.

\title{
Strategic Situational Planning Applied to the Venezuelan Social-Economic Sector
}

\begin{abstract}
The objective of this article is to present the results obtained in the application of the Situation Planning Model (SPM) in the Venezuelan socio-economic environment, under the dynamic of policies that were applied during the year 2000. The methodology employed was exploratory, documentary and descriptive, since the application of this Situation Planning Model requires the same. The results of the research after applying all the analytical explanatory, documentary and descriptive instruments, indicate that the alternative strategic action which promoted situational change in order to resolve the concrete problem selected, which was unemployment, was the project called "Promotion and support for emerging business entrepreneurs", which generated a greater dynamic effect on the economy. As strategies for process characterization, the application of dialogue, bargaining, and alliance (cooperation and co-optation) discussion tables was stressed and generated the appropriate political climate that favored the adequate application of the project.
\end{abstract}

Key words: Planning, situation, strategy, policy, unemployment, emerging business entrepreneurs.

\section{Introducción}

Hace ya aproximadamente tres décadas, el profesor chileno Carlos Matus, especialista en Alta Dirección y Planificación Estratégica, graduado con post grado en la hoy Kennedy School of Government, introduce la Planificación Estratégica Situacional como método de planificación de las políticas públicas durante el gobierno de Salvador Allende, cuyo nacimiento epistemológico se genera de la crítica a los argumentos metodológicos que sustentaban a la planificación tradicional o normativa como instrumento de apoyo para alcanzar el desarrollo.

Durante los años venideros a la década del setenta, bajo el ejercicio como director del PNUD/Naciones Unidas, ase- sor del Ministerio de Hacienda en Venezuela, donde se refugia luego del golpe Militar que depone y asesina a Allende, continúa su labor como investigador y consolida su propuesta.

El presente estudio utiliza el enfoque metodológico del citado profesor Carlos Matus, en el sistema económico social y político venezolano, para hacer un análisis situacional de los problemas que afectaban al país durante los años 2000 - 2001 y definir cuáles eran las políticas más idóneas que el gobierno debió activar para mitigar y eliminar las demandas sociales que más afectaban al colectivo durante esa época.

Para ello, se transita por los tres primeros momentos del enfoque estratégico situacional, ya que el momento último, el 
Planificación situacional aplicada al sector socioeconómico venezolano Alizo, María Alexandra; Graterol, Angela; Añez, Silenis y Ríos, Marisela

cuatro o táctico operacional, abarca la implementación y monitoreo de las políticas a aplicar y, por supuesto, la responsabilidad recae sobre el actor social capaz de generar el cambio a través de la acción concertada, conciente y no rutinaria, en este caso, el gobierno.

Haciendo una recopilación breve de la taxonomía metodológica en la que se desagrega la PES (Planificación Estratégica Situacional), es importante señalar que la misma trabaja por instancias denominadas momentos. Cada una posee instrumentos característicos pero no de uso exclusivo, ya que pueden ser utilizadas por las otras como soporte para la toma de decisiones acertada.

El trabajo se inicia transitando por el momento explicativo (M1) en donde se procede a realizar un breve diagnóstico situacional del sistema, para lo cual se hace uso de la data estadística, informes financieros del Banco Central de Venezuela (BCV), información del Plan de Desarrollo Bolívar 2000, anuarios estadísticos de la Oficina Central de Estadística e Información (OCEI), entre otros. Asimismo, se proyectaron algunos de los datos de las variables macroeconómicas para conocer las tendencias y analizar hacia dónde se dirige, en forma natural, el sistema.

Una vez hecho el respectivo diagnóstico, se sistematizó su contenido haciendo uso de la matriz del análisis de las Fortalezas, Oportunidades, Debilidades y Amenazas (FODA) y se procedió a jerarquizar los problemas tratando de considerar la perspectiva de los diferentes actores. Para ello, se evaluaron las demandas sociales insatisfechas (debilidades y amenazas) a través de la Matriz de
Valuación de los Problemas por los Actores, la cual utiliza varios criterios para realizar la selección, a saber: valor político del problema, tiempo de maduración de los resultados, recursos disponibles para su enfrentamiento, gobernabilidad, costo de postergación, exigencia de innovación e impacto político sobre la gestión resolutiva del problema.

Con la instrumentalización de la Matriz de Valuación de los Problemas por los Actores se pudo conocer que el inconveniente que más afecta a los venezolanos es la falta de oportunidades de trabajo (Desempleo). Por su parte, la complejidad del proceso de selección de los problemas requirió de un estudio inicial exploratorio, ya que involucró la participación de varios de los actores dentro del objeto de estudio que fue planificado.

Ya definido el problema de mayor relevancia para los venezolanos, se procedió a desarrollar la técnica de explicación gráfica o flujograma situacional sobre el problema concreto elegido. A través de este instrumento se logró identificar los nudos explicativos causales de este problema y, partiendo que es el Estado quien goza de la mayor cantidad de recursos para solucionar e intervenir sobre el sistema, se procedió a identificar los nudos críticos (NC) causales que mayoritariamente están agudizando el desempleo dentro del país.

Posteriormente, en el transitar del momento normativo (M2), donde se precisan los proyectos estratégicos de acción de carácter direccional (PY's), se identificaron las acciones estratégicas que podrían ejercer un mayor efecto positivo para mitigar y solventar el desempleo dentro del sistema. 
De este modo, se propuso como parte del Programa Direccional del desempleo a los siguientes proyectos estratégicos de acción de carácter direccional (PY's):

- PY1: Fomento y Apoyo a las emprendedores emergentes de negocios (Proyecto: EEN).

- PY2: Reabrir el proceso de apertura (licitación) a la inversión privada nacional y extranjera (Proyecto: Plataforma IT).

- PY3: Promover la operativización de los programas de los ejes o polos de desarrollo estratégico (Proyecto: PDE).

- PY4: Promover el desarrollo endógeno del sistema (Proyecto: Desarrollo Endógeno).

En el transcurso de esta instancia del modelo PES o momento normativo (M2), se evaluaron cada una de las propuestas o de los proyectos de acción estratégica a través de las matrices de Proyectos Estratégicos de Acción Direccional - Problemas (Matriz PY's-Pr's) y la de los Actores Intervinientes, instrumentos metodológicos estos de soporte para la toma de decisiones dentro del modelo referencial.

Del análisis coadyuvado de las matrices, se dedujo cuál era el proyecto que generaba un mayor impacto positivo dentro de los nudos críticos vinculantes a la geno y fenoestructura del flujograma situacional del desempleo. Además de seleccionar aquel que generara la menor intervención de actores sociales con intereses contrapuestos a los del gobierno. Por lo tanto, resultaría un proyecto relativamente sencillo implementarlo en el sistema económico social venezolano.
En este orden de ideas, al abordar el último momento considerado en esta investigación, el M3 o el momento estratégico, se pudo constatar el nivel de resistencia o de restricciones situacionales por parte de otros actores. La aplicación del modelo en el momento tres permitió generar las estrategias de carácter procesal o PX's que deben implementarse para neutralizar el efecto opositor al desarrollo del proyecto, tal como se verá cuando se expongan los resultados de la presente investigación.

Cabe hacer la salvedad que la investigación no contempló el impacto del "hacer" o momento táctico - operacional (M4). Sin embargo, es oportuno señalar que actualmente el Centro de Investigaciones Económicas y Sociales de La Universidad del Zulia desarrolla una investigación donde se aborda parte de este tema.

Por último, es importante resaltar que la investigación se inicia en el marco de la cooperación interinstitucional entre la Gobernación del Estado Apure y la Universidad del Zulia en el año de 1999, con el propósito de asesorar sobre el tipo de políticas públicas más idóneas para promover y estimular el desarrollo de la "Economía Popular".

A tal efecto, se estimó conveniente hacer un estudio preliminar, denominado análisis situacional, bajo la concepción de la planificación de situaciones. El mismo buscaba determinar cuales eran los problemas más relevantes para la población venezolana. Es, como repuesta a todas estas inquietudes, que surge la idea de aplicar el proceso de planificación de situaciones al contexto económico social venezolano. Los resultados denotan un aporte al indicar una direccionalidad con- 
Planificación situacional aplicada al sector socioeconómico venezolano Alizo, María Alexandra; Graterol, Angela; Añez, Silenis y Ríos, Marisela

creta a políticas cuyo norte era imprevisible en esos momentos, sobre todo en el ámbito o contexto concreto donde se inicia el proceso, el estado de Apure.

\section{Planificación Estratégica Situacional-Bases Teóricas}

La PES se define como un proceso social destinado a diseñar un conjunto articulado de acciones no rutinarias de un actor social (llámese gobierno, sociedad civil, empresarios, estudiantes, entre otros) con posibilidad de intervenir sobre la realidad para que, dadas ciertas limitaciones y en presencia de oponentes, el sistema cambie de una situación inicial ( $\mathrm{Si}$ ) hacia una situación objetivo (So) acorde o en concordancia a un "proyecto nacional" del grupo político que ostenta el poder (Ver Diagrama 1).

La planificación de situaciones es una repuesta a la incapacidad de producir cambios sustanciales por parte de la planificación normativa. El concepto de si- tuación es el punto pilar del proceso. La importancia que le da Carlos Matus (1987) a la situación, como eje del procedimiento estratégico, coincide con el concepto de situación en la planificación de la guerra. Es decir, tanto la planificación de situaciones como la planificación de guerra son procesos que se derivan de la planificación estratégica.

La situación, la cual será el objeto de análisis y transformación, presenta dos componentes: la FENOSITUACIÓN que es donde se producen los hechos observables a través del sentido común; y la GENOSITUACIÓN que es donde se generan las leyes estructurales del sistema (Corredor, 1997:149).

En la FENOSITUACIÓN actúan fuerzas sociales, éstas a su vez son agrupaciones con capacidad y voluntad de acción que poseen o controlan recursos de poder. En la GENOSITUACIÓN están las estructuras, tales como: la económico-social que representa el modo de producción material, político-jurídico son institu-

\section{Diagrama 1 \\ Modelo de Planificación Estratégica Situacional}

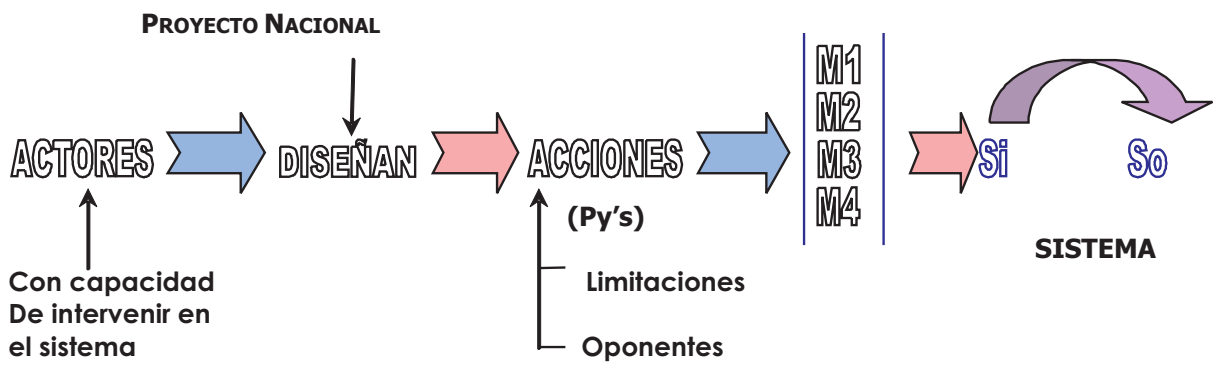

Fuente: Elaboración propia. 
ciones, normas y disposiciones cuyo objeto es regular el funcionamiento de la situación. Aquí se establecen las relaciones de poder y, por último, la estructura ideológica, la cual es el conjunto de valores que configura una praxis tradicional, presente y futura (Corredor, 1997:149).

La situación actúa en un escenario, sistema más amplio el cual le comprende y determina. En la situación se configuran los antagonismos de las fuerzas sociales que luchan por mantener la genosituación y las que luchan por transformarla, mediante la aproximación y consolidación de una imagen objetivo previamente construida.

"La planificación de situaciones consiste en aplicar el poder de una o varias fuerzas sociales para producir el cambio social. Con este propósito, el método propone la secuencia de cuatro momentos: Explicativo, normativo, estratégico y táctico-operacional" (Corredor, 1996: 149).

- Momento Explicativo (M1): Palabras clave: fue, es, tendería a ser. El investigador planificador examina la situación y define los problemas existentes, para la discusión de todas las fuerzas sociales afectadas, y configurar lo que en la planificación normativa se conoce como "diagnóstico". La explicación, en este método, es más dinámica, puede variar aún sin haber concluido el momento. Su verdadero sentido es establecer las relaciones causales de los problemas (Corredor, 1997:152).

- Momento Normativo (M2): Palabras clave: Debería Ser.

Equivale al proceso que sigue la planificación normativa. Consiste en la formulación del debe ser o del "diseño del plan" y su producto terminal es el trazado de trayectorias y direcciones de aproximación a la situación objetivo (Corredor, 1997:152).

- Momento Estratégico (M3): Palabras Clave: Puede Ser?

Se refiere al análisis y la construcción de la viabilidad del plan. Atiende fundamentalmente al oponente, pues crear viabilidad no es más que determinar quiénes se oponen a los proyectos y disminuir o eliminar sus acciones o presiones. Este es el centro vital de la planificación estratégica. Por eso, se considera indispensable conocer, en profundidad, las raíces políticas, económicas y sociales que determinan una sociedad; la magnitud del poder y los términos en que se puedan desarrollar las negociaciones de un conflicto o de un consenso (Matus, 1987:511).

- Momento Táctico-operacional (M4): Palabra Clave: Hacer!

Es el de la ejecución de las estimaciones y los cálculos. Es el momento que precede y preside la acción concertada. Se relaciona con el Sistema de Dirección Estratégica y con sus respectivos Subsistemas. Su centro es la gerencia, que se inicia con la organización de los recursos. Aquí se consideran tres básicamente: técnicos, financieros y de poder. En este momento de definen y deciden las operaciones que se ejecutarán para solucionar los problemas planteados. Se establecerán las formas de control y evaluación de lo que se está realizando y la retroalimentación de los cálculos y de las acciones en movimiento (Matus, 1987:624). 
Planificación situacional aplicada al sector socioeconómico venezolano

Alizo, María Alexandra; Graterol, Angela; Añez, Silenis y Ríos, Marisela

\section{Metodología}

Para aplicar la Planificación de Situaciones al ámbito económico social venezolano se realizó un estudio de tipo exploratorio - documental y descriptivo, soportado en la aplicación de tres fuentes de recolección de información. La primera, la revisión bibliográfica de data económica y social de los anuarios del Banco Central de Venezuela y de la antigua Oficina Central de Estadística e información, hoy el (Instituto Nacional de Estadística), estos fueron soportes para conocer los históricos concretos que define Carlos Matus y, en definitiva, proporcionan las tendencias o sinergias del sistema.

La segunda, las referencias directas obtenidas mediante la conformación de "mesas de trabajo" con agentes del gobierno de esa época, componentes de la sociedad civil y de la organización no gubernamental (ONG) denominada Fundación de Desarrollo Popular (FUDEP), los cuales fueron informantes claves referenciales para seleccionar los problemas de mayor impacto según lo precisa la Matriz de Jerarquización de los problemas por los actores. Es importante acotar que durante esa época el Teniente Coronel Jesús Aguilarte era adjunto al Presidente de la República, el Teniente Coronel Hugo Chávez Frías para la promoción de lo que se denominaba el $D e-$ sarrollo de la Economía Popular, la cual fue génesis de lo que hoy se conoce con el nombre del desarrollo de la economía endógena.

Asimismo, las mesas de trabajo fueron un instrumento para sistematizar los causales del problema del desempleo, que posteriormente, se sintetizan en el instrumento denominado Flujograma Situacional del momento explicativo del modelo.

La tercera, la apreciación de técnicos expertos quienes participaron en la selección cualitativa de los nudos críticos del problema, los cuales fueron básicos para la selección del programa direccional del momento normativo y el consecuente proyecto estratégico direccional de acción, según lo arrojado por otro instrumento analítico, como lo es el análisis de sensibilidad, el cual selecciona de los nudos explicativos del problema, aquellos que generen un mayor impacto real sobre su vector descriptor (VDP).

Se indica que es un estudio de tipo documental porque paralelamente se recurrió a la constrastación teórica-práctica sustentada en el modelo de Planificación de Situaciones propuesto por Carlos Matus. Por su parte, es descriptivo, porque una vez aplicados los instrumentos de cada uno de los momentos se hace un análisis de los resultados de la investigación.

El resultado de este proceso se podría resumir en la aplicación de un análisis metodológico de triangulación positivista, en el cual convergen por un lado un estudio exploratorio para conocer las alternativas de políticas en el sistema, otro de confrontación teórico-práctico que busca estructurar e intervincular el Modelo de Soporte de Decisiones Públicas propuesto por Carlos Matus con la realidad inherente en la realidad venezolana de la época; y por el otro, un estudio descriptivo donde se exponen los resultados de la aplicación de la Planificación Estratégica para definir el proyecto de mayor efecto dinamizador dentro de la economía. 


\section{Exposición de los Resultados de la Aplicación de la PES}

Para muchos, resulta repetitivo hacer un diagnóstico de cuales son los principales problemas que afectan al sistema económico-social y político venezolano. Por lo tanto, se buscará limitar la exposición a ofrecer un cuadro resumen del análisis FODA del sistema según los resultados obtenidos durante el transitar en la instancia explicativa del modelo PES.

De esta manera, el Cuadro 1 muestra en forma sinóptica los puntos fuertes y débiles, internos y externos, claves y característicos del desenvolvimiento de la economía del país.

Debido a que fue en el período de 2000-2001 el marco referencial para tomar las decisiones sobre las acciones a seguir durante el quinquenio correspondiente siguiente, ya que el conocimiento precede a la acción, en el sucesivo segmento se hace un breve análisis de cómo se desarrollaba el sistema según el estado histórico concreto que mostraban las variables macroeconómicas y sociales.

La economía venezolana se ha basado principalmente en la explotación del petróleo y sus derivados. En las últimas décadas tiende a diversificarse con exportaciones de mineral de hierro, aluminio, carbón, cemento y productos no tradicionales, como materias petroquímicas, manufacturas metálicas de acero y otras.

Hasta comienzos de la década de 1980, Venezuela obtuvo una alta renta petrolera de origen externo, que permitió al Estado elevar constantemente su gasto sin aumentar la tributación interna, dis- frutando la población de un alto nivel de vida con una notable mejora de los servicios de salud y educación.

Asimismo, se logró una industrialización interna que sustituía muchas importaciones, la construcción de una importante infraestructura viaria, de regadío e hidroelectricidad y la formación de grandes empresas públicas.

Sin embargo, a partir de 1989 se producen una serie de hechos que conmueven y sacuden a la nación venezolana con acontecimientos dramáticos que tuvieron su expresión en lo que se conoció con el nombre del "Caracazo" y, posteriormente, con la "intentona golpista" del 4 de febrero de 1992, lo que produjo una gran desestabilización en todos los sentidos, especialmente "inestabilidad política", la cual fue consecuencia directa del descrédito de los partidos políticos existentes, los cuales, se ven a los ojos del pueblo, como los culpables de la gran crisis económica en la que estaba sumida Venezuela, a consecuencia de la mala gestión administrativa del Estado, donde se había desaprovechado el modelo rentista-petrolero y se malgastaron las riquezas a manos de funcionarios corruptos que contribuyeron al empobrecimiento de un sector importante del país. El problema económico trasciende sus límites hasta llegar al ámbito político, donde la mayoría de las formas institucionales son cuestionadas por la metástasis de la crisis económica.

Posteriormente, se produce una caída sostenida del ingreso petrolero, el cual se redujo a un tercio en 1993, acompañado con altos pagos en la deuda pública externa y una sostenida presión financiera por la salida de recursos mone- 
Planificación situacional aplicada al sector socioeconómico venezolano Alizo, María Alexandra; Graterol, Angela; Añez, Silenis y Ríos, Marisela

tarios internacionales, que culminó en 1994 con una grave crisis bancaria, con altos niveles, nuevamente, de corrupción administrativa y un descenso en la calidad de vida para los grupos o sectores más desposeídos.

En ese tiempo se implantó una nueva política económica neoliberal, que se materializó en la nueva devaluación del signo monetario, la liberalización de los precios internos y de las tasas de interés, el inicio de la privatización de empresas públicas y la renegociación de la deuda externa. Sin embargo, la presión económica vivida, la recesión y el estancamiento de la economía, fue acompañada de una convulsión política y social, que finalizó en la salida intespectiva del presidente de ese entonces, Carlos Andrés Pérez.

En el año de 1996 se produce un cambio económico en el que se acentúa la privatización de empresas públicas deficitarias, el estímulo a la inversión extranjera en varias industrias, como la petrolera, petroquímica, minería del oro, diamantes, carbón, níquel, explotación forestal, turismo y otros sectores, que se expresa además con la libertad de precios y de adquisición de divisas.

A partir de 1999, un nuevo gobierno asume el poder y con él una serie de cambios comienzan a gestarse dentro del sistema económico social. Se convoca a la población a un referéndum consultivo para modificar la base legal venezolana contemplada en la Constitución Nacional. De este modo, se produce un cambio a nivel fenoestructural de las leyes que rigen el sistema, se convoca nuevamente a elecciones para ratificar los nuevos poderes públicos establecidos y darles legiti- midad (Asamblea Nacional Constituyente, 1999).

En el plano económico, se produce un giro dentro de los lineamientos de política donde juega un rol determinante la reestructuración del Estado y de sus empresas, se establece como meta el control de los niveles de inflación, lo cual repercute en el crecimiento del PIB agudizando la recesión y el desempleo.

Con el objetivo de dinamizar al aparato productivo venezolano se procede implementar un conjunto de políticas de estímulo a la "Economía Popular" insertas dentro del Plan de Desarrollo Bolívar 2000 , donde se busca estimular el desarrollo mediante el otorgamiento de créditos a aquellas iniciativas de inversión que generen impacto dentro de las diferentes regiones del país, fundamentalmente dando prioridad a aquellas zonas de menor concentración de población y con alto potencial de recursos, para estimular el empleo y la producción.

Según los resultados del marco referencial que dio origen al Plan Bolívar 2000 y 2001, los problemas internos más relevantes para la población venezolana se podrían resumir en los siguientes: estancamiento del PIB, inflación, desempleo, inseguridad social, pobreza crítica, crisis del sector salud, déficit fiscal, crisis del sistema educativo, endeudamiento externo y dicotomía entre el desarrollo del campo y la ciudad (MPD, 2001).

La Planificación Estratégica Situacional se inicia formalmente con el proceso de selección de problemas y es éste el objeto último de la realización de las instancias anteriores. La selección de problemas es una tarea creativa y 
descentralizada. En cada nivel jerárquico es necesario focalizar la atención en la tarea de enfrentar los problemas que le sean propios.

En el plano del gobierno central, se hace una selección de megaproblemas y de problemas que, por su complejidad y alcance, requieren de la participación de varias organizaciones. Sin embargo, la primera dificultad consiste en identificar correctamente estos problemas, y no confundirlos con temas problemáticos, con objetivos o metas, o con operaciones de las cuales se está convencido que se deben realizar y continúan postergándose (Matus, 1998: 178).

Justamente, es necesario realizar todos los procesos preliminares para garantizar el conocimiento apropiado del objeto planificado y, de esta manera, poder identificar cuáles son los cuellos de botella que más afectan al sistema y que se tratarán de resolver. A Continuación se presenta el FODA de los principales problemas que aquejan a la población venezolana, según el análisis de las fuentes claves consultadas en la investigación (Ver Cuadro 1).

Un problema expresa una insatisfacción, una inconformidad con la realidad presente o sus perspectivas futuras. Esa insatisfacción llega a ser un problema cuando un actor lo declara inevitable y lo incluye en su agenda. El calificativo de inevitable lo convierte en parte del paisaje social. Sólo los actores pueden declarar problemas (Matus, 1998: 179).

La población no organizada tiene necesidades sin peso político, hasta el momento en que se organiza o un actor declara el problema en su nombre. Si el actor tiene gobernabilidad sobre el problema puede incluirlo en su agenda para enfrentarlo como parte de su proyecto de gobierno. Si no tiene gobernabilidad, puede emplear su fuerza política para denunciarlo.

Todo problema llega a los actores sociales negativamente afectados como un malestar impreciso. Llega a formularse como problema sólo cuando es descrito con propiedad, es decir, es desagregado en indicadores cualitativos y cuantitativos en lo que se conoce como su marcador o evidencia empírica de su existencia (Matus, 1998: 178).

Resulta importante señalar que para la construcción de la Matriz de Jerarquización de los Problemas por los Actores más relevantes del sistema (ver Tabla 1), las amenazas no se tomaron en cuenta debido a que son problemas externos, es decir, que escapan al control de los actores internos y que dependen mayoritariamente de fuerzas exógenas al sistema muy vinculadas a los intereses de otros ámbitos internacionales que, aún cuando resultan importantes en un mundo globalizado, en este estudio preliminar e interno, se obviaron.

La Matriz de Jerarquización de los Problemas por los Actores (Matriz Pr's$P y$ 's) es un instrumento metodológico que fortalece el esfuerzo por seleccionar, sustentado sobre la base de un conjunto de criterios que permiten una sistematización más objetiva, de las demandas sociales que se deban urgentemente que enfrentar según la perspectiva de ciertos actores de interés para el sujeto planificador. Así, los criterios utilizados fueron los siguientes (Matus, 1998:179): 
Planificación situacional aplicada al sector socioeconómico venezolano Alizo, María Alexandra; Graterol, Angela; Añez, Silenis y Ríos, Marisela

\section{Cuadro 1 \\ Resultados del análisis de la matriz FODA en el sistema venezolano}

\begin{tabular}{|c|c|}
\hline Fortalezas & Oportunidades \\
\hline $\begin{array}{l}\text { - Cierto nivel de desarrollo industrial en la trans- } \\
\text { formación de materia prima proveniente de los } \\
\text { recursos naturales que posee el país. } \\
\text { - Alto potencial para el desarrollo turístico. } \\
\text { - Bajo costo de la mano de obra. } \\
\text { - Se cuenta con vías de comunicaciones terres- } \\
\text { tres, acuáticas y aéreas. Asimismo, alto de- } \\
\text { sarrollo de telecomunicaciones. } \\
\text { - Mejora del clima político luego del proceso de } \\
\text { relegitimación de los poderes, lo cual contribu- } \\
\text { ye positivamente en la calificación del riesgo } \\
\text { país. } \\
\text { - El presupuesto del } 2001 \text { está dirigido en su } \\
\text { mayoría a los gastos de inversión y gasto pro- } \\
\text { ductivo. }\end{array}$ & $\begin{array}{l}\text { - Abundantes recursos naturales renovables y } \\
\text { no renovables. } \\
\text { - Ubicación geográfica excelente, lo cual favo- } \\
\text { rece el intercambio comercial internacional. } \\
\text { - Intensificación de los procesos de integración, } \\
\text { entre ellos: La Comunidad Andina, El Grupo } \\
\text { Tres, ALADI, MERCOSUR, con tendencias a } \\
\text { una globalización. } \\
\text { - Población activa altamente joven. } \\
\text { - Elevado Desarrollo Mundial de las Telecomu- } \\
\text { nicaciones lo cual facilita la internacionaliza- } \\
\text { ción de las relaciones comerciales. } \\
\text { - Intensificación del las Alianzas estratégicas } \\
\text { con sistemas no tradicionales }\end{array}$ \\
\hline Debilidades & Amenazas \\
\hline $\begin{array}{l}\text { - Economía monoproductiva altamente depen- } \\
\text { diente de las fluctuaciones de los precios del } \\
\text { mercado petrolero. } \\
\text { - Elevados niveles de subempleo y desempleo } \\
\text { dentro de la población. } \\
\text { - Escasa cultura tributaria del venezolano. } \\
\text { - Servicios Públicos muy deficientes. } \\
\text { - Alto niveles de inseguridad Social. } \\
\text { - Cultura paternalista altamente enraizada en la } \\
\text { mentalidad del ciudadano común. } \\
\text { - Pérdida de valores dentro de la población por } \\
\text { crisis en el sector educativo. } \\
\text { - Dicotomía entre el desarrollo del campo y la } \\
\text { ciudad, la concentración del } 85 \% \text { de la pobla- } \\
\text { ción está localizada en el } 7 \% \text { del territorio na- } \\
\text { cional. }\end{array}$ & $\begin{array}{l}\text { - Alta dependencia del sector externo (tanto } \\
\text { para las exportaciones, como para las impor- } \\
\text { taciones). } \\
\text { - Pérdida de la competitividad mundial de los } \\
\text { productos factibles de exportación por fuentes } \\
\text { alternativas energía. } \\
\text { - El impacto del Plan Colombia. } \\
\text { - Ola de especulaciones a nivel internacional } \\
\text { sobre la existencia interna de un gobierno de } \\
\text { corte comunista. } \\
\text { - Incremento de los pagos por servicio de la } \\
\text { deuda externa. } \\
\text { - Litigio con Guyana. } \\
\text { - Penetración de la guerrilla. } \\
\text { - Puente del narcotráfico internacional de estu- } \\
\text { pefacientes. } \\
\text { - Lluvias prolongadas sobre territorio venezola- } \\
\text { no. }\end{array}$ \\
\hline
\end{tabular}

Fuente: Elaboración propia. 
Tabla 1

Matriz de jerarquización de los problemas por los principales actores sociales

\begin{tabular}{|c|c|c|c|c|c|c|c|c|c|c|c|c|c|c|c|c|c|}
\hline \multirow{2}{*}{ Actores } & \multicolumn{8}{|c|}{ Actor 1} & \multicolumn{8}{|c|}{ Actor 2} & \multirow[b]{2}{*}{ Total } \\
\hline & VP & TM & $\mathbf{R}$ & G & $\mathrm{CP}$ & INN & IP & $\begin{array}{l}\text { Sub- } \\
\text { Total }\end{array}$ & VP & TM & $\mathbf{R}$ & G & $\mathrm{CP}$ & INN & IP & $\begin{array}{l}\text { Sub- } \\
\text { Total }\end{array}$ & \\
\hline $\operatorname{Pr} 1$ & 2 & 1 & 1 & 1 & 2 & 1 & 2 & 10 & 1 & 1 & 1 & 1 & 1 & 1 & 1 & 7 & 17 \\
\hline Pr 2 & 2 & 2 & 2 & 1 & 2 & 1 & 2 & 12 & 2 & 1 & 1 & 1 & 2 & 1 & 2 & 10 & 22 \\
\hline Pr 3 & 2 & 2 & 2 & 1 & 2 & 2 & 2 & 13 & 2 & 2 & 2 & 1 & 2 & 1 & 2 & 12 & 25 \\
\hline $\operatorname{Pr} 4$ & 2 & 1 & 2 & 2 & 2 & 1 & 2 & 12 & 2 & 1 & 2 & 1 & 2 & 1 & 2 & 11 & 23 \\
\hline $\operatorname{Pr} 5$ & 2 & 2 & 2 & 1 & 2 & 1 & 2 & 12 & 2 & 1 & 1 & 1 & 2 & 1 & 2 & 10 & 22 \\
\hline $\operatorname{Pr} 6$ & 2 & 1 & 2 & 1 & 2 & 1 & 2 & 11 & 2 & 1 & 1 & 1 & 2 & 1 & 2 & 10 & 21 \\
\hline $\operatorname{Pr} 7$ & 1 & 2 & 1 & 2 & 2 & 1 & 2 & 11 & 1 & 1 & 0 & 0 & 1 & 1 & 1 & 5 & 16 \\
\hline $\operatorname{Pr} 8$ & 2 & 1 & 2 & 1 & 2 & 1 & 2 & 11 & 2 & 1 & 1 & 1 & 2 & 1 & 2 & 10 & 21 \\
\hline $\operatorname{Pr} 9$ & 1 & 0 & 2 & 2 & 1 & 1 & 1 & 8 & 1 & 1 & 0 & 0 & 1 & 1 & 1 & 5 & 16 \\
\hline Pr10 & 1 & 1 & 2 & 1 & 1 & 0 & 1 & 7 & 1 & 1 & 1 & 1 & 1 & 1 & 1 & 7 & 14 \\
\hline
\end{tabular}

Fuente: elaboración propia.

Donde:

Pr1 = Estancamiento del PIB

Pr2 = Inflación

Pr3 = Desempleo

Pr4 = Inseguridad Social

Pr5 = Pobreza Crítica

Pr6 = Crisis en el Sector Salud

Pr7 = Déficit Fiscal

Pr8 = Crisis del Sistema Educativo

Pr9 = Endeudamiento Externo

Pr10 = Dicotomía entre el desarrollo del Campo y la Ciudad
Actor 1 = Gobierno PRESIDIDO POR:

- Teniente Cnel. Jesús Aguilarte

- Dr. Yvette Pérez

- Econ. Domingo J. Méndez

Actor 2 = Sociedad Civil PRESIDIDO POR:

- Econ. Elsy Faria (FUDEP)

- Estudiantes de LUZ y de la Universi-dad Católica André Bello.

- Profesores (LUZ y U. Católica)

- Trabajadores informales

- Población Civil

senta, el partido político del actor, la población en general y la población directamente afectada.

2. El Tiempo de Maduración de los Resultados (TM): Este factor, trata los otros actores a los cuales el repre- 
Planificación situacional aplicada al sector socioeconómico venezolano

Alizo, María Alexandra; Graterol, Angela; Añez, Silenis y Ríos, Marisela

de concretar el lapso de tiempo probable en el cual se podrá mostrar un cambio significativo en las metas propuestas. En este sentido, es importante señalar si los resultados significativos se lograrán fuera o dentro del período de gobierno, fuera o dentro del tiempo humano (una generación) o fuera o dentro del tiempo social (varias generaciones).

3. Recursos Disponibles para el Enfrentamiento del Problema (R): Representa el grado de coherencia entre la disponibilidad de poder político, recursos económicos, recursos cognitivos y capacidades organizativas bajo el control del actor que realiza el proceso de planificación y el grado en que esos mismos recursos son exigidos por el plan que enfrenta el problema.

4. Gobernabilidad sobre el Problema (G): Es un criterio que esclarece el grado de dificultad política del problema al precisar si las causas del problema seleccionado están principalmente fuera o bajo el control de los actores que planifican.

5. Costo de Postergación del Problema (CP): Implica un juicio anticipado del costo político, económico, social, entre otros, en el cual se incurriría en el período del proceso de planificación si el problema es excluido del plan. La valoración de este costo será generalmente distinta si se trata de una oportunidad una amenaza o un problema ya creado.

6. Exigencia de Innovación (INN): Es una característica que facilita o atemoriza la toma de decisiones de la dirigencia política. El error en política es costoso y la innovación tiene siempre una significativa probabilidad de falla inicial. El político busca seguridad en las decisiones críticas y la innovación lo atemoriza.

7. Impacto Político Sobre La Gestión (IP): Se refiere a un criterio de síntesis que obliga a pronosticar, en base a todos los criterios anteriores, el balance de contribución del plan sobre el problema en los tres cinturones de gobierno, a saber:

- Impacto político positivo o negativo sobre el balance de gestión política, - Impacto político positivo o negativo sobre el balance de intercambio de problemas específicos,

- Impacto positivo o negativo sobre el balance macroeconómico.

Sin duda, la complejidad del proceso de selección de problemas, aún cuando es un asunto exclusivo del equipo planificador, requiere de un estudio exploratorio inicial, tal como se señaló anteriormente, ya que involucra a otros actores que, de una u otra forma, participan y co-existen dentro del objeto que está siendo planificado.

En este caso, se trabajó en mesas de trabajo con representantes de cada sector en concreto, del gobierno y de la sociedad civil. Los resultados indicaron que era el desempleo el problema de más relevancia para la población venezolana, con una calificación promedio de 25 puntos, tal como lo muestra la Tabla 1, en la cual se exponen los resultados promedios de una muestra de 30 personas representantes de cada sector (gobierno y sociedad civil).

A continuación, se procedió a elaborar el flujograma situacional del desempleo, para lo cual se trabajó con la 
realidad latente durante el período 20002001. Las cifras de esa época indicaban que el desempleo era de aproximadamente del 13 por ciento de la población económicamente activa (13\% de la población económicamente activa - PEA).

El flujograma situacional es la representación gráfica que ayuda a sistematizar el conocimiento sobre la realidad de un problema, previo a su selección. Indica la intervinculación entre los diferentes nudos explicativos del problema y permite identificar a través del análisis de sensibilidad aquellos nudos críticos que tienen un mayor efecto sobre el Vector Descriptor del Problema (VDP).

El Flujograma Situacional está compuesto, tal como se muestra en el Esquema 1, por tres partes principales. La primera contiene la sistematización del problema por parte de los actores que realizan la planificación. Aquí se hace un esbozo que se inicia con la identificación de los factores que han incidido en el origen del problema (y que lo continúan afectando) o Genoestructura, las acumulaciones sociales o Fenoestructura y los hechos concretos causales del problema en cuestión o Fenoproducción. A este primer cuadrante del Flujograma Situacional se le denomina explicación situacional y permite la perspectiva de visualización de los nudos explicativos en cada nivel situacional del problema.

La segunda contiene a los Descriptores o al Vector Descriptor del Problema $(V D P$,) en la cual se ubican los indicadores que nos ratifican la presencia del problema. La tercera parte del Flujograma Situacional está conformada por los efectos que genera el que el problema exista en la realidad (ver Esquema 1).

\section{Esquema 1} Partes componentes del Flujograma Situacional

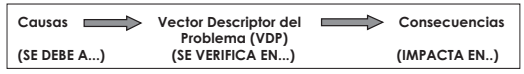

Fuente: Matus, 1998: 184.

La explicación gratificada del problema es de una gran potencia informativa y obliga a una alta precisión. El Diagrama 2 (ver página siguiente), donde se hace una reconstrucción visual del problema del desempleo, permite dilucidar una síntesis conclusiva de los argumentos que respaldan la construcción del flujograma, como herramienta analítica idónea para visualizar la dimensión de un problema concreto.

Entre los argumentos más relevantes que justifican la elaboración de esta matriz se encuentran los siguientes: el permitir identificar el marcador del problema, las causas y sus relaciones, las consecuencias, el grado de gobernabilidad del actor(es) sobre el problema, según sea la concentración y peso de las causas críticas en los cuadrantes 1, 2 y 3 , el grado de dificultad del problema, según sea la concentración de las causas críticas en las reglas (genoestructura), las acumulaciones (fenoestructura) y los flujos (fenoproducción), las causas que pueden ser nudos críticos (análisis sensibilidad) del problema, es decir, aquellas donde la acción es más práctica y eficaz, la vía por la cual la remoción o atenuación de las causas críticas o nudos críticos permite al actor afectar el marcador o VDP del problema y avanzar hacia las metas (nuevo marcador del problema) y el peso que tiene la cooperación de otros 
Planificación situacional aplicada al sector socioeconómico venezolano Alizo, María Alexandra; Graterol, Angela; Añez, Silenis y Ríos, Marisela

Diagrama 2

Flujograma situacional del desempleo. Nudos críticos Situación inicial: $13 \%$ PEA

\begin{tabular}{|l|l|l|l|l|l|}
\hline Genoestructura \\
delamiento Modelo \\
rentista
\end{tabular}

Fuente: Elaboración propia.

actores para alcanzar el nuevo marcador del problema (plan dual).

Es importante añadir que este flujograma situacional ya contiene intrínsecamente el análisis de sensibilidad, por lo tanto, los cuadrantes explicativos sobre los cuales el gobierno no tiene inherencia fueron ya sustraídos.

Asimismo, se ha hecho un proceso cualitativo de selección para únicamente considerar aquellos nudos explicativos que, aparte de ser controlados por el actor o sujeto planificador (en este caso la perspectiva es a nivel de gobierno), ejerzan un mayor nivel de afectación sobre el descriptor del problema.

Por otra parte, a través del Diagrama 2, el cual representa una forma de percibir el problema del desempleo dentro de esta sociedad, se puede captar como la mayor cantidad de nudos críticos causales se encuentran ubicados dentro de los dos primeros niveles situacionales: geno y fenoestructura.

De esta manera, el agotamiento del modelo rentístico (NC1) y la ruptura de la equidad presupuestaria (NC2) son subproblemas que dentro de la matriz representan las causas origen o genoestructurales del problema del desempleo.

En contraparte, la recesión económica (NC3), las malas prácticas gerenciales (NC4), cultura paternalista del estado venezolano (NC5), políticas económicas restrictivas (NC6), la crisis política (NC7), falta de planificación en la educa- 
ción (NC8) y el fracaso de los programas y proyectos sociales constituyen los acumulados sociales y, consecuentemente, demandas sociales insatisfechas preámbulo para que se produzca y acentúe el desempleo en el país.

En total, de los catorce nudos críticos seleccionados como causales del problema objeto de estudio, nueve están dentro de los dos primeros niveles situacionales que presentan mayor complejidad (genoestructura y fenoestructura) ya que son los que generan las condiciones para que se presenten hechos concretos más simples, pero también causales, como lo son los nudos críticos de la fenoproducción.

En la fenoproducción se ubican los causales más fáciles de solventar y, por lo tanto, con menor tiempo de maduración para lograr resultados y movilizar el marcador del problema. Es este el nivel situacional preferido de los que están en gobierno, ya que pueden provocar alteraciones rápidas, de forma, pero que en definitiva no resuelve los causales de fondo que están generando los hechos que se ven reflejados en este nivel situacional.

Para el problema del desempleo las causas de la fenoproducción son las siguientes: disminución de la inversión pública, cierre de empresa, la generación de profesionales sin demanda de empleo, la fuga de capital y la muy baja productividad de los proyectos nacionales.

En el vector descriptor del problema del desempleo (VDP), que representa en última instancia la situación que se desea cambiar, se encuentra la descripción de los diferentes indicadores que miden la magnitud del problema. Para este caso en particular es la tasa de crecimiento del índice general del desempleo, el desempleo de la población económicamente activa desagregada por edad y sexo, y el nivel que asume el subempleo. Es precisamente este indicador el que se busca movilizar mediante la (ver Diagrama 2).

Las consecuencias del problema también se ven reflejadas dentro del flujograma situacional. En la medida que la magnitud del problema sea mayor, habrá más o menor concentración de impactos en este cuadrante. Así, en el flujograma situacional que se analiza se puede identificar como el desempleo contribuye a informalizar la fuerza de trabajo, incrementa los niveles de pobreza crítica, los niños de la calle, la violencia familiar, la deserción escolar, el hacinamiento familiar, así como otros problemas de origen psico social.

Es sobre la base de este instrumento del momento explicativo (M1) que se busca definir los proyectos estratégicos de acción de carácter direccional del momento normativo (M2), con el objetivo de provocar un cambio positivo dentro del sistema respecto a este problema en particular. Cabe hacer la salvedad que este modelo trabaja, a diferencia de la planificación normativa, problema por problema.

Sin embargo, antes de transitar la segunda instancia situacional, el momento normativo (M2), se procedió a realizar una matriz de gran importancia ya que proporciona información básica de cuales son los indicadores, cualitativos y cuantitativos, de los nudos críticos identificados como causales del problema del desempleo. De esta manera, el Cuadro 3 evidencia las referencias informativas de seguimiento para no perder de perspectiva los causales del problema. 
Planificación situacional aplicada al sector socioeconómico venezolano Alizo, María Alexandra; Graterol, Angela; Añez, Silenis y Ríos, Marisela

Una vez alcanzados los objetivos durante la trayectoria por el momento explicativo, se comienza a preparar el programa base o a precisar los lineamientos generales sobre los cuales se abordaría el problema. Para la presente investigación, fueron los presentados en el Plan de Desarrollo Bolívar 2001 los que se constituyeron en el marco referencial básico para generar el Programa Direccional Sectorial del Desempleo. En este nivel se hizo necesario precisar cual era la diferencia entre un programa base y el direccional, ambos instrumentos pertenecientes al momento normativo (M2).

El momento normativo (M2) consiste en la formulación del "debe ser" y su producto terminal es el trazado de trayectorias y direcciones de aproximación a la situación objetiva. Ello requiere la formulación de los Proyectos Estratégicos de Acción, pero de carácter direccional (Py's) ya que, en última instancia, son estas acciones las que buscarán alcanzar la situación objetivo.

Asimismo, el programa base expresa la direccionalidad general que un actor quiere imprimirle al cambio de la situación presente. Pero tal propuesta no cubre la totalidad relevante para la acción, ni tiene dimensionamiento riguroso. Es un recurso comunicativo en busca de apoyo, por lo que no expresa la discordancia que puede existir entre objetivos y medios (Matus, 1987:424).

Dentro del ejercicio investigativo que se ha desarrollado, el programa base abarcaría a todo el sector que está siendo objeto del proceso de planificación. A modo de ejemplo, el programa base, definido sobre el mayor nivel de agregación y síntesis, sería el marco general acucioso del Proyecto Bolivariano 2001-2002 dentro de un contexto que supedita lo económico sobre lo político-social, el cual se sintetiza a continuación:

"Diversificar el modelo económico objeto de estudio promoviendo la producción y exportación de otros sectores productivos que cuentan con ventajas comparativas y competitivas, para de esta forma lograr la recuperación y estabilización del sistema y una consecuente mejor distribución del ingreso".

Tal como se aprecia en el ejemplo, el programa base propuesto es genérico y no establece ni el cómo, cuándo, dónde, con qué y quiénes desarrollarán la acción. Es más un proceso direccional genérico que de una forma sencilla, busca establecer los límites y/o bandas sobre los cuales se movilizarán las posibles alternativas de acción del proceso y, en consecuencia, los posibles proyectos que conformarán el Programa Direccional de Acción, punto que se iniciará a continuación.

El programa direccional se define operativamente como la propuesta de un actor por la cual, explica la situación inicial, define la situación objetivo y precisa normativamente los proyectos estratégicos de acción de carácter direccional (Py's) necesarios y suficientes para alterar a la situación de partida (Si) y alcanzar a So. Es un insumo para definir y diseñar la estrategia en donde no se consideran los oponentes activos explícitos del proceso.

El programa direccional define y precisa el arco direccional, ya que establecerá con mucha exactitud los medios y recursos para lograr ciertos resultados, según los escenarios previamente planteados por el equipo planificador para tratar de solucionar el problema del desempleo. 


\section{Cuadro 3 \\ Matriz nudos críticos. Indicadores para el problema del desempleo}

\begin{tabular}{|c|c|c|}
\hline No. NC & Descripción & Indicadores \\
\hline & G $E$ & $\begin{array}{llllllll}S & T & R & U & C & T & U & R \\
\end{array}$ \\
\hline 1 & $\begin{array}{l}\text { Agotamiento } \\
\text { del modelo } \\
\text { rentístico }\end{array}$ & $\begin{array}{l}\text { - Tasa de Crecimiento del PIB a precios constantes } \\
\text { - Tasa de Crecimiento de los Ingresos públicos } \\
\text { - Tasa de Crecimiento de la Acumulación del Capital }\end{array}$ \\
\hline \multirow[t]{2}{*}{2} & $\begin{array}{l}\text { Ruptura de } \\
\text { equidad } \\
\text { presupuestaria }\end{array}$ & $\begin{array}{l}\text { - Relación entre los Ingresos y Egresos Públicos } \\
\text { - Tasa de Crecimiento del Déficit Presupuestario } \\
\text { - Tasa de Crecimiento de los Ingresos y Egresos Públicos }\end{array}$ \\
\hline & $\mathrm{F} E$ & 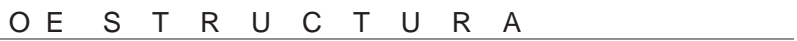 \\
\hline 3 & $\begin{array}{l}\text { Recesión } \\
\text { Económica }\end{array}$ & $\begin{array}{l}\text { - Tasa de Crecimiento del PIB } \\
\text { - Tasa de Crecimiento de la Inversión pública y privada } \\
\text { - Tasa de Crecimiento del Consumo }\end{array}$ \\
\hline 4 & $\begin{array}{l}\text { Malas Prácticas } \\
\text { Gerenciales }\end{array}$ & $\begin{array}{l}\text { - Relación entre el No. de empresas de más de } 100 \text { trabajadores } \\
\text { que han sobrevivido durante } 45 \text { años o más y el No. de empre- } \\
\text { sas totales } \\
\text { - Índice de Productividad Empresarial. }\end{array}$ \\
\hline 5 & $\begin{array}{l}\text { Cultura } \\
\text { paternalista } \\
\text { del Estado }\end{array}$ & $\begin{array}{l}\text { - Análisis de los históricos y variedades de los subsidios } \\
\text { - Efectividad y progresividad del real del tributo venezolano } \\
\text { - No. total de programas de asistencia gubernamental }\end{array}$ \\
\hline 6 & $\begin{array}{l}\text { Políticas } \\
\text { Económicas } \\
\text { Restrictivas }\end{array}$ & $\begin{array}{l}\text { - Análisis de la política económica nacional a través de las tasas } \\
\text { de crecimiento del Ingreso y Egresos Públicos, M2, Interés Acti- } \\
\text { vo y Pasivo, Emisiones Públicas, Tipo de Cambio, Inflación, In- } \\
\text { versión, otras. }\end{array}$ \\
\hline 7 & Crisis Política & $\begin{array}{l}\text { - Tasa de Riesgo - País } \\
\text { - Nivel de conflictividad política entre los principales sectores } \\
\text { - Nivel de crecimiento de la inversión y/o acumulación de Capital }\end{array}$ \\
\hline 8 & $\begin{array}{c}\text { Falta de } \\
\text { planificación } \\
\text { en la Educación }\end{array}$ & $\begin{array}{l}\text { - No. de Reformas de Carreras Ofertadas en las Universidades } \\
\text { - No. de Reformas a la Ley de Educación en los } 10 \text { últimos años } \\
\text { - Nivel de Efectividad de los cambios (Diferentes Indicadores) }\end{array}$ \\
\hline \multirow[t]{2}{*}{9} & $\begin{array}{l}\text { Fracaso de los } \\
\text { programas } \\
\text { sociales }\end{array}$ & $\begin{array}{l}\text { - No. de Programas Autofinanciados y Autogestionados } \\
\text { - No. de Programas Sociales con más de } 10 \text { años de vigencia } \\
\text { - Tasa de Crecimiento de la Pobreza Crítica }\end{array}$ \\
\hline & $\mathrm{F} \quad \mathrm{E} N \mathrm{~N}$ & 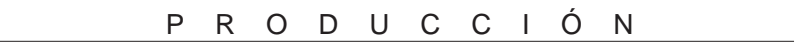 \\
\hline 10 & $\begin{array}{l}\text { Disminución } \\
\text { de la inversión } \\
\text { pública }\end{array}$ & $\begin{array}{l}\text { - Tasa de Crecimiento de la Inversión Pública } \\
\text { - No. de personas despedidas del Sector Público } \\
\text { - Nivel del recorte Presupuestario de Gastos de Inversión Esta- } \\
\text { dal }\end{array}$ \\
\hline
\end{tabular}


Planificación situacional aplicada al sector socioeconómico venezolano Alizo, María Alexandra; Graterol, Angela; Añez, Silenis y Ríos, Marisela

\section{Cuadro 3 (continuación) Matriz nudos críticos. Indicadores para el problema del desempleo}

\begin{tabular}{|c|c|c|}
\hline No. NC & Descripción & Indicadores \\
\hline 11 & Cierre de empresas & $\begin{array}{l}\text { - No. total de empresas quebradas en los últimos } 5 \text { ó } 10 \text { años. } \\
\text { - Tasa de Crecimiento de la Inversión. } \\
\text { - Tasa de Desocupación laboral. }\end{array}$ \\
\hline 12 & $\begin{array}{l}\text { Profesionales } \\
\text { sin demanda }\end{array}$ & $\begin{array}{l}\text { - Tasa de Población Económicamente Activa Desocupada. } \\
\text { - Desempleo por edad y sexo. } \\
\text { - Nivel del Subempleo. }\end{array}$ \\
\hline 13 & $\begin{array}{l}\text { Disminución de la } \\
\text { Inversión Privada }\end{array}$ & $\begin{array}{l}\text { - Tasas de Crecimiento de la Inversión Privada. } \\
\text { - No. de personas despedidas del sector privado. } \\
\text { - No. total de empresas cerradas. }\end{array}$ \\
\hline 14 & $\begin{array}{l}\text { Baja operatividad } \\
\text { de los proyectos }\end{array}$ & $\begin{array}{l}\text { - No. total de proyectos aprobados por ejecutivo y paralizados. } \\
\text { - Registro del tiempo de espera entre la ejecución de los proyec- } \\
\text { tos y la puesta en marcha. }\end{array}$ \\
\hline
\end{tabular}

Fuente: Elaboración propia.

En función de todos estos aspectos que han sido aclarados, se procederá, ahora sí, a enunciar las Acciones Estratégicas Direccionales (Py's) que conformararon parte del Programa Direccional Sectorial para buscar resolver los elevados niveles de desempleo dentro del sistema.

\section{Situación Inicial:}

El partido en el Gobierno de este sistema vive una situación difícil; el país está en recesión económica, inflación, desinversión con desconfianza institucional y la desocupación crece a pasos agigantados. La popularidad del gobierno decrece.

\section{Situación Objetivo:}

Los sujetos planificadores elaboran un programa direccional para recuperar la adhesión y confianza popular en la gestión del gobierno, la cual buscará estabilizar y reactivar el aparato productivo del sistema, sin que se des- borde la inflación, se recupere los niveles de ocupación y que no se deteriore significativamente el nivel de reservas internacionales por la aplicación de estas acciones.

Programa Direccional (Problema del Desempleo):

- PY1: Fomento y Apoyo a las iniciativas emergentes de negocios a través del otorgamiento de créditos a corto y mediano plazo (3 meses a 3 años) a una tasa que permita el autofinanciamiento del proyecto a través del retorno de la inversión garantizada mediante la asesoría técnica a los beneficiarios últimos del programa, es decir, a los Emprendedores Emergentes de Negocios (Proyecto: EEN).

- PY2: Reabrir el proceso de apertura (licitación) a la inversión privada nacional y extranjera, para agilizar los procesos de creación de la infraestructura física turística necesaria para imprimirle dinamismo a aquellas zo- 
nas evaluadas con enorme potencial para el desarrollo de esta actividad (Proyecto: Plataforma IT).

- PY3: Promover la operativización de los programas de los ejes o polos de desarrollo estratégico en áreas, tales como: Eje Guajira - La Guardia, Eje Orinoco - Apure, Eje Bolívar - Oriente, entre otros (Proyecto: PDE).

- PY4: Promover el desarrollo endógeno del sistema, mediante el estímulo y apoyo a las fuerzas productivas no tradicionales nacionales, pero con ventajas competitivas y comparativas que favorezcan el crecimiento y expansión de estas economías paralelas dentro del sistema (Proyecto: Desarrollo Endógeno).

Para jerarquizar y determinar los proyectos que ejercen un mayor impacto sobre el problema del desempleo, se procedió a elaborar la Matriz de Problemas Proyecto Estratégicos de Acción de Carácter Direccional (ver matriz Pr's - Py's en el Cuadro 4). Cabe señalar que este proceso se realiza porque no siempre se cuentan con los medios pertinentes y necesarios para ejecutar todas las acciones estratégicas formuladas. Por consiguiente, se deben precisar cuales de las acciones estratégicas direccionales son las más efectivas con los recursos y bajo las condiciones actuales que presente el sistema.

Por otro lado, se debe realizar la matriz con el flujograma situacional del desempleo, ya incorporado el análisis de sensibilidad, para poder establecer si la acciones estratégicas direccionales definidas (PY1, PY2, PY3 y PY4) ejercen algún impacto positivo o negativo sobre las principales demandas o nudos críticos que explican el problema e identificar la ubicación de los diferentes nudos críticos. Así tenemos que:

FS Desempleo = NC1+NC2+NC3+NC4+ $\mathrm{NC} 5+\mathrm{NC} 6+\mathrm{NC} 7+\mathrm{NC} 8$ $\mathrm{NC9}+\mathrm{NC} 10+\mathrm{NC} 11+$ $\mathrm{NC} 12+\mathrm{NC} 13+\mathrm{NC} 14$

Donde,

- Nudos Críticos de la Genoestructura: NC1 - NC2

- Nudos Críticos de la Fenoestructura: NC3 - NC4 - NC5 - NC6 - NC7 - NC8 - NC9 - Nudos Críticos de la Fenoproducción: NC10 - NC11 - NC12 -NC13 - NC14

Los resultados arrojados de la construcción de la matriz (ver cuadro 4) indicaron que el proyecto estratégico de acción que ejercía una mayor influencia o impacto sobre el problema del desempleo era el número uno o Proyecto EEN, con un total de afectación de diez nudos críticos.

Según estos resultados preliminares, se pudo deducir que es el PY1 el que representaba la acción estratégica que se seleccionó como prioritaria. Pero el análisis fue un poco más allá. Adicionalmente, hubo que analizar la ubicación de los nudos críticos en el flujograma situacional que se estaba afectando.

Es decir, se determinó a que nivel situacional pertenecían cada uno de los nudos críticos impactados, pues cada nivel dentro del flujograma situacional representa un grado de complejidad diferente $y$, de este modo, es mucho más adecuado seleccionar aquella acción cuya afectación se agrupe sobre la genoestructura y fenoestructura, niveles situacionales éstos donde se concentran las demandas sociales de mayor importancia. Así, al complementar el Cuadro 4 se obtuvieron los siguientes resultados: 
Planificación situacional aplicada al sector socioeconómico venezolano Alizo, María Alexandra; Graterol, Angela; Añez, Silenis y Ríos, Marisela

\begin{tabular}{|c|c|}
\hline \multicolumn{2}{|c|}{ Matriz problemas. Proyectos estratégicos de acción del Programa } \\
Direccional del Desempleo
\end{tabular}

Fuente: Elaboración Propia.

\section{PY1 = 10 NC afectados}

$1 \mathrm{NC}$ ubicados en la genoestructura $4 \mathrm{NC}$ ubicados en la fenoestructura $5 \mathrm{NC}$ ubicados en la fenoproducción PY2= 9 NC afectados

$2 \mathrm{NC}$ ubicados en la genoestructura 2 NC ubicados en la fenoestructura 5 NC ubicados en la fenoproducción

\section{PY3= 5 NC afectados}

$1 \mathrm{NC}$ ubicado en la genoestructura

$0 \mathrm{NC}$ ubicados en la fenoestructura

4 NC ubicados en la fenoproducción

\section{PY4= 9 NC afectados}

1 NC ubicado en la genoestructura 3 NC ubicados en la fenoestructura 5 NC ubicados en la fenoproducción

Tal como se evidencia, el proyecto estratégico de acción de carácter direccional que afectaba mayoritariamente los niveles situacionales de mayor relevancia dentro del flujograma situacional del desempleo era el Proyecto ENN, por lo cual según el modelo PES debería ser el seleccionado como acción prioritaria por ser la más eficiente.

El análisis podría finalizar con esta matriz, sin embargo, existen otros instrumentos que se realizan para dar un mayor soporte al proceso de jerarquización de la importancia que tiene la acción concertada sobre los problemas, que aún cuando a los efectos de éste trabajo sólo se estaba abordando un sólo problema, se hizo imperioso el considerarlos.

Uno de esos otros instrumentos es la Matriz de los Actores Intervinientes (ver Tabla 2) que se analiza a continuación. Esta matriz se constituyó en un complemento básico para la toma de decisión pertinente sobre la selección de la acción que fuese la más adecuada. 


\section{Tabla 2}

Matriz de los actores intervinientes para el Programa Direccional Sectorial del Desempleo

\begin{tabular}{|c|c|c|c|c|}
\hline ACTORES INTERVINIENTES & $\begin{array}{l}\text { PY1 } \\
\text { Proyecto } \\
\text { ENN }\end{array}$ & $\begin{array}{c}\text { PY2 } \\
\text { Proyecto } \\
\text { Plataforma } \\
\text { IT } \\
\end{array}$ & $\begin{array}{l}\text { PY3 } \\
\text { Proyecto } \\
\text { PDE }\end{array}$ & $\begin{array}{c}\text { PY4 } \\
\text { Proyecto de } \\
\text { desarrollo } \\
\text { Endógeno }\end{array}$ \\
\hline \multicolumn{5}{|c|}{ ACTORES CONTROLABLES } \\
\hline Presidente de República & 1 & 1 & 1 & 1 \\
\hline Ministerio de Finanzas & 1 & 1 & 1 & 1 \\
\hline Asamblea Nacional & 1 & 1 & 1 & 1 \\
\hline Otros Ministerios & 0 & 1 & 1 & 1 \\
\hline Corporaciones regionales & 1 & 1 & 1 & 1 \\
\hline Gobernaciones & 1 & 1 & 1 & 1 \\
\hline \multicolumn{5}{|c|}{ ACTORES NO } \\
\hline $\begin{array}{l}\text { Organismos Multilaterales } \\
\text { de financiamiento }\end{array}$ & 1 & 0 & 0 & 1 \\
\hline Organismos No Gubernamental (ONG) & 1 & 0 & 1 & 1 \\
\hline Sector Bancario Nacional & 0 & 1 & 1 & 0 \\
\hline Sociedad Civil & 1 & 1 & 1 & 1 \\
\hline Inversionista Nacional & 1 & 1 & 1 & 1 \\
\hline Inversionista Extranjero & 0 & 1 & 1 & 0 \\
\hline Centros de Educación & 1 & 1 & 1 & 1 \\
\hline Medios de Difusión & 1 & 1 & 1 & 1 \\
\hline Partidos de Oposición (A. Nacional) & 1 & 1 & 1 & 1 \\
\hline Totales Actores Controlable & 5 & 6 & 6 & 6 \\
\hline Totales Actores No Controlable & 7 & 7 & 8 & 7 \\
\hline
\end{tabular}

Fuente: Elaboración propia.

La Matriz de los actores intervinientes se define como un esquema teórico práctico para el análisis, que en forma gráfica, permite la identificación de todos aquellos actores controlables y no controlables que participan e intervienen activamente en los desarrollos de los proyectos estratégicos de acción de carácter direccionales que están siendo analizados.

La forma de construcción de la matriz es muy sencilla. Lo primero que se debió realizar fue la identificación de los actores controlables o no controlables que participarían proactiva o reactivamente en la implementación de todos los PY'S propuestos, que en este caso eran cuatro (PY1-PY2-PY3-PY4).

A los actores se los colocó en el extremo izquierdo de las filas, de manera vertical, previa identificación de si eran actores controlables o no por el sujeto planificador de este proceso. Cabe recor- 
Planificación situacional aplicada al sector socioeconómico venezolano Alizo, María Alexandra; Graterol, Angela; Añez, Silenis y Ríos, Marisela

dar que se estaba planificando desde la perspectiva de un actor y éste posee aliados y ejerce influencia sobre ciertos actores adeptos a sus proyectos sectoriales particulares.

Luego, se abrieron las columnas donde se identificaron los proyectos estratégicos de acción propuestos, que como ya se expresó eran cuatro. Estos se ubicaron en la parte superior, en perspectiva o línea horizontal. La escala aplicada en el cuadro sólo revelaba dos alternativas posibles: 1) interviene, simbolizada con uno (1) y, 2) no interviene, con cero (0).

Es importante resaltar que la matriz además de indicar cuales son los actores que participan en el proceso, proporciona la posibilidad de analizar si se tiene o no influencia sobre estos. Además, esta información será valiosa para el apéndice siguiente (elaboración del plan) donde se identificaron las responsabilidades de los actores que intervendrían en la ejecución e implementación del proyecto que resultara seleccionado.

Por otra parte, una vez concluida la elaboración de esta matriz, se les dio preferencia al PY que involucró menor cantidad de actores intervinientes no controlables, dado que la gobernabilidad para desarrollar dicha acción sería mas probable y posible.

Es decir, el propósito final de la elaboración de la matriz fue el de elegir aquellos proyectos de acción estratégica cuya gobernabilidad por parte de los actores que interviniesen fuese la mayor, para de alguna manera garantizar la puesta en marcha y viabilidad del proyecto direccional de acción. La reagrupación de los actores estuvo en función a la ca- pacidad de control por parte del equipo planificador.

Tal como se evidencia en la matriz de los actores intervinientes (ver Tabla 2) los proyectos estratégicos de acción propuestos presentaban similitudes en cuanto a los participantes activos y necesarios para la implementación de las acciones. No obstante, el Proyecto EEN era el que presentaba una menor intervención de actores controlables, al no requerir la participación de los otros ministerios diferentes al de Finanzas y Planificación (reflejado en la participación de las corporaciones regionales de desarrollo). Mientras que para implementar los otros PY'S se requería la coordinación de todo el resto de sectores públicos, dada la envergadura de las acciones a desarrollar.

De este análisis también se podría desprender que las otras acciones resultarían de mayor relevancia, pero es importante recordar que, en primera instancia, se estaba tratando de jerarquizar acciones y seleccionando aquellas cuyos impactos fuesen mayores, con un uso eficaz y eficiente de recursos disponibles.

Si bien es cierto que esas acciones involucraban participación activa de mayores actores del sector público, también lo es el hecho de que el Proyecto EEN resultó el de mayor impacto positivo sobre los nudos críticos del problema que se buscaba mitigar (ver Cuadro 4).

Por otra parte, respecto a los actores controlables, se pudo visualizar que solamente el proyecto de fomento de polos de desarrollo (PY3) presentaba una participación activa de ocho actores sociales (todos a excepción de los organismos multilaterales internacionales de financiamiento). Los restantes PY'S incor- 
poraban respectivamente siete actores sociales activos.

Es importante añadir que la naturaleza del actor fue relevante analizarla, ya que si éste resultaba ser un actor de naturaleza opositora y clave para el desarrollo del proyecto, así este proyecto presentase menor cantidad de actores intervinientes, era posible que la decisión de rechazo o de preferencia hacia algún otro proyecto, estuviese supeditada a aspectos o factores como éste.

Al analizar los actores no controlables que participaban en el Proyecto FAMI, resaltó un aspecto, que a juicio de los planificadores, resultó muy interesante. El Proyecto ENN no requería de inversionistas extranjeros, cuyo control escapa casi totalmente de las autoridades del país donde se vaya a ejecutar la acción estratégica. La inversión extranjera se mueve en función de intereses y beneficios que éstos puedan obtener de las inversiones de sus capitales. Esto hacía que el proyecto EEN se convirtiese en una acción de naturaleza totalmente nacional lo que facilitaría su control, al proporcionar autonomía y gobernabilidad en el largo plazo.

Ya para sintetizar, a través del análisis coadyuvado de las matrices Pr's Py's y la de los actores intervinientes se pudo concluir que el Proyecto de Fomento y Apoyo a los Empresarios Emergentes de Negocios o Microempresarios, resultaba ser de prioridad y, en consecuencia, se exhortaba a seleccionarlo como propuesta gubernamental de acción estratégica direccional para disminuir los niveles de desempleo que según reza en cifra inicial, para este sistema en el año 2001, superaba al 13 por ciento de la población económicamente activa.
En cuanto a la posibilidad real de implementar este proyecto, durante el transitar por el momento tres (M3) o estratégico, donde se realizó la Matriz de Análisis y Construcción de la Viabilidad (ver Cuadro 5), se pudo confirmar que la acción estratégica recomendada presentaba, como es natural, cierto nivel de restricción situacional por parte de algunos actores intervinientes, pero de peso participativo menor.

Es decir, el análisis de la viabilidad que se define como el proceso mediante el cual se evalúan los espacios direccionales que invaden los proyectos estratégicos direccionales seleccionados por el actor que planifica, de modo que se pueda puntualizar cuáles serán las actitudes de esos otros actores, cuya intervención es esencial, pero sus intereses contrastan con las del que quiere ejecutar la transformación.

Para realizar este proceso, es conveniente precisar la relevancia y peso que tienen esos otros actores cuya participación es básica para la operativización adecuada del proyecto. Para ello se hizo necesario realizar la evaluación de los PY'S a implementar según la metodología que evalúa los espacios direccionales de cada uno de esos actores sociales.

La Matriz del Análisis de la viabilidad es un instrumento gráfico que permite dilucidar sistemáticamente sobre las posturas que asumen cada uno de los actores intervinientes. De manera que, mediante un esquema sinóptico se pueda establecer, con cierto nivel de exactitud y organicidad, la importancia, postura y participación de los actores, respecto al proyecto que se desea implementar dentro de la realidad. 
Planificación situacional aplicada al sector socioeconómico venezolano Alizo, María Alexandra; Graterol, Angela; Añez, Silenis y Ríos, Marisela

A través de este instrumento se lograba facilitar el análisis de las posibles restricciones situacionales que debe afrontar el planificador. La construcción fue relativamente fácil y, al igual que en las otras instancias, se requirió la interacción con los otros momentos. Para su elaboración se necesitó:

- Identificar claramente cada uno de los diferentes actores intervinientes para desarrollar el proyecto de acción direccional. A este respecto, en el proyecto EEN participan: Presidente de la República, Ministerio de Finanzas, Ministerio de Planificación, Asamblea Nacional, Organismos Laterales y Multilaterales, Nacionales e Internacionales de Financiamiento (OLMF), Corporaciones Regionales, Gobernaciones, Banca estadal, Banca Privada, Organismos no Gubernamentales (ONG), Sociedad Civil, Medios de Comunicación, Organizaciones PYMES, Partidos Políticos de Oposición y Universidades Nacionales.

- Tener un conocimiento real sobre la dinámica actual de interacción social de los actores participantes en el contexto donde se desarrolla el proceso de planificación, para definir la inclinación, respecto a la relevancia y peso sobre la factible implementación del PY en cuestión.

- Hacer la evaluación respectiva a través del uso de la matriz (Cuadro 5).

Los actores intervinientes, tal como lo muestra el Cuadro 4, se colocaban verticalmente en el eje de las filas para proceder a realizar la evaluación respectiva.

El proceso de examen del interés y valor combinó el conocimiento de la realidad, la intuición, las técnicas de análisis sociopolítico, con la experticia del planificador. No existe una regla básica para desarrollar este proceso. Sin embargo, el Cuadro 5 fue construido de acuerdo a lo que el grupo planificador creía era la realidad del sistema que se estaba analizando.

Respecto al vector de peso, puede apreciarse que absolutamente todos los actores que están incluidos participarían en la posible ejecución del proyecto EEN, lo cual se puede corroborar en el vector al aportar algún tipo de recursos en específico. Es decir, el número o valor que asume la participación o contribución de los actores participantes al proveer un porcentaje de recursos políticos (\%RP), recursos financieros (\%RF) y recursos organizativos e institucionales (\%ROI).

Tal como lo ilustra el Cuadro 5, el vector de peso muestra que para desarrollar un proyecto como EEN, es necesario contar con el $100 \%$ de los recursos políticos, económicos y organizativos - institucionales. Por lo tanto, se debió identificar quienes eran los actores que preveían esos recursos en el proyecto de empresarios emergentes de negocios.

La forma real en que participan esos actores para suministrar esos recursos indica el peso y responsabilidad que tienen los actores en el proyecto que se deseaba realizar. Así, en forma agregada se pudo dilucidar que los actores con mayor peso son los siguientes, según la síntesis presentada en la Tabla 3.

De estos actores, sólo las gobernaciones no tienen una correspondencia positiva con el proyecto nacional bolivariano, por lo tanto, pueden presentar alguna motivación negativa. Esto se explica partiendo que el sistema es uninomi- 


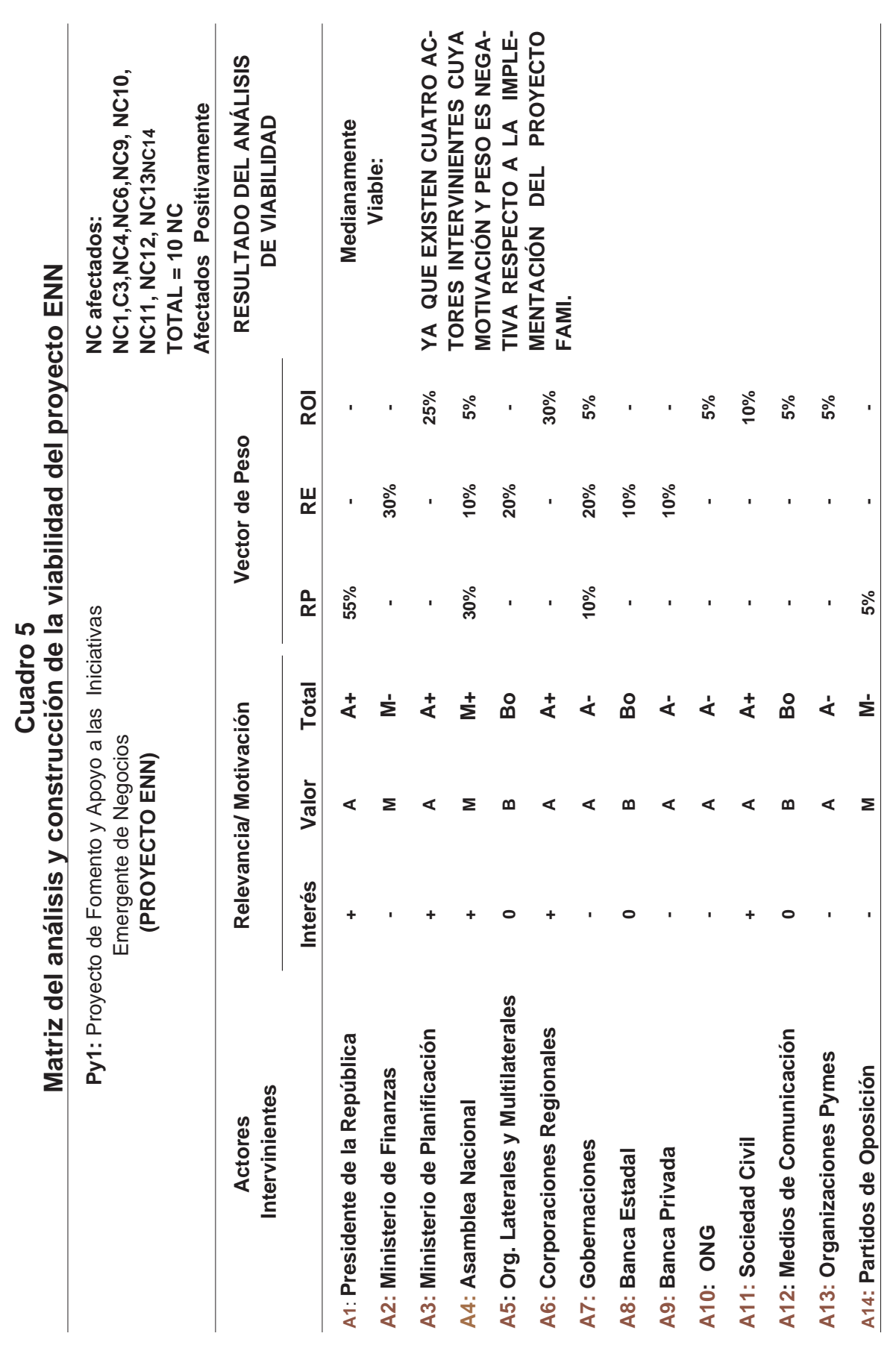


Planificación situacional aplicada al sector socioeconómico venezolano

Alizo, María Alexandra; Graterol, Angela; Añez, Silenis y Ríos, Marisela

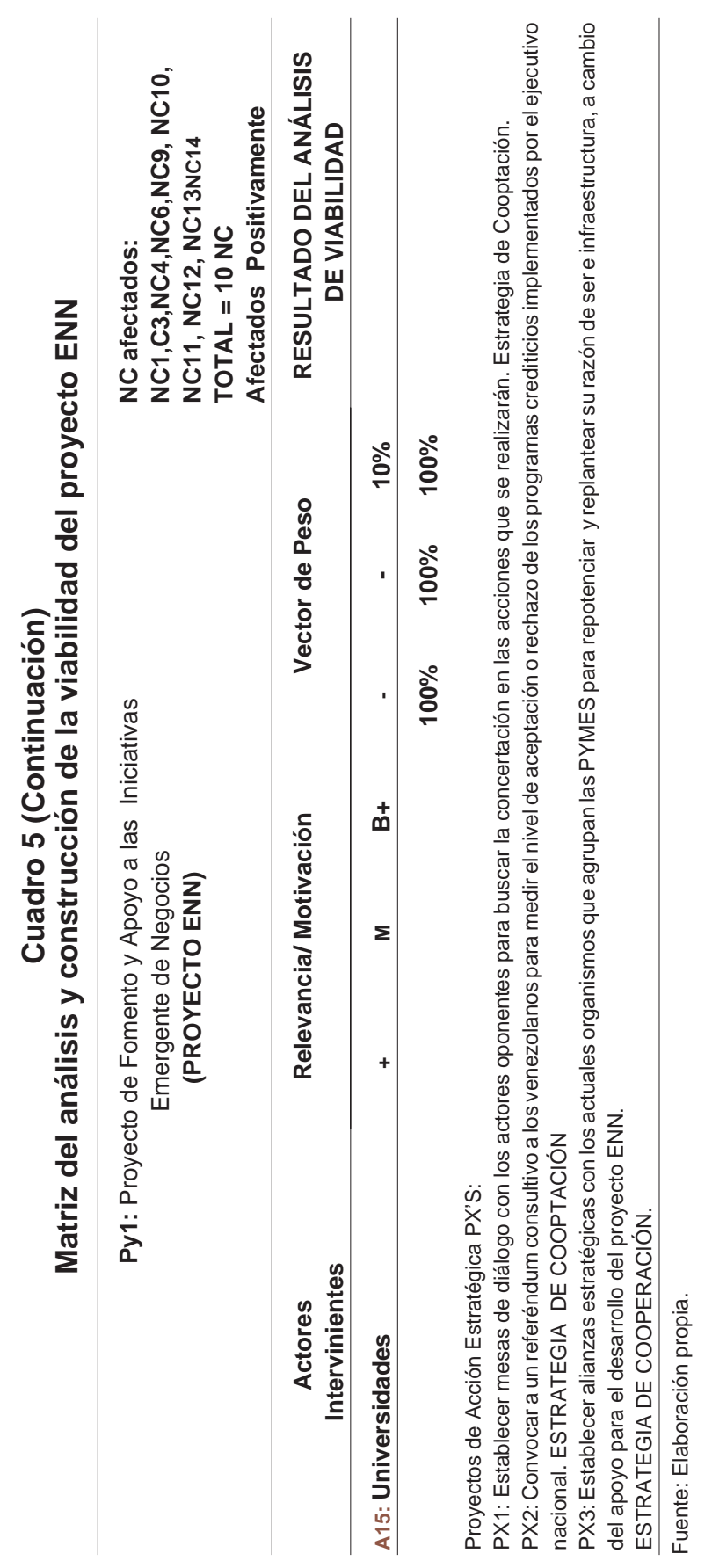


nal y democrático, entonces podría resultar factible que los gobernadores estadales no sean adeptos al gobierno central. En este caso, el planificador, que pertenece al gobierno central, deberá diseñar alguna estrategia de construcción de viabilidad, debido a la importancia que tiene este actor para el desarrollo exitoso del proyecto. Es esto lo que se conoce con el nombre de Proyectos Estratégicos de Acción de Carácter Procesal (PX's) cuyo diseño es el objetivo último de este momento (M3).

El análisis del cuadro 5 no se finalizó aquí, ya que existían otros actores que, aún cuando tenían menor peso para el desarrollo del proyecto, sus motivaciones podrían ser altamente negativas, con lo cual se convertirían en potenciales obstáculos para la realización del cambio económico-social. Tal era el caso de las ONG, Banca Privada, Organizaciones PYMES y Partidos de Oposición.

En forma acumulativa ellos proveen apenas un $30 \%$ de recursos (repartidos desigualmente en políticos, económicos e institucionales), pero quizás tendrían acceso a los medios de comunicación y otras vías que podrían atentar contra el proyecto. En la planificación no hay enemigo pequeño, es necesario evaluar todas las alternativas y diseñar estrategias procesales considerando las realidades del sistema. Un hábil planificador no debería obviar ningún detalle.

Al realizar una síntesis del momento estratégico (M3) se puede apreciar que la matriz del análisis de la viabilidad trabaja conjuntamente con los responsables y participantes activos de los módulos operativos y de los planes duales del momento normativo (M2), a la vez que involucra el momento explicativo (M1) ya que debe tener un conocimiento muy certero de la realidad y la dinámica del juego político, pero todo con la mira en la implementación del plan, o momento táctico-operacional (M4), con el propósito último de infringir un cambio social en la realidad.

El propósito de este momento estratégico es el diseño de estrategias de construcción de viabilidad, o lo que es lo mismo precisar los proyectos estratégicos de acción de carácter procesal (PX'S) que romperán con las barreras o restricciones situacionales del Programa Direccional, que en este caso es el desempleo.

Cuando se presentan barreras situacionales, el planificador debe diseñar

Tabla 3

Importancia de los actores intervinientes según la matriz de análisis de viabilidad

\begin{tabular}{lcccc}
\hline Actores Intervinientes & Peso total & RP & RF & ROI \\
\hline A1: Presidente de la República & $55 \%$ & $\mathbf{5 5 \%}$ & - & - \\
A4: Asamblea Nacional & $45 \%$ & $\mathbf{3 0 \%}$ & $\mathbf{1 0 \%}$ & $\mathbf{5 \%}$ \\
A7: Gobernaciones & $35 \%$ & $\mathbf{1 0 \%}$ & $\mathbf{2 0 \%}$ & $\mathbf{5 \%}$ \\
A6: Corporaciones Regionales & $30 \%$ & - & - & $\mathbf{3 0} \%$ \\
\hline
\end{tabular}

Fuente: Elaboración propia. 
Planificación situacional aplicada al sector socioeconómico venezolano Alizo, María Alexandra; Graterol, Angela; Añez, Silenis y Ríos, Marisela

otras estrategias que busquen construir viabilidad a los proyectos estratégicos direccionales que no la tengan. De este modo, existen tres tipos de estrategias de construcción de viabilidad para un programa direccional (Matus, 1987:519):

1. Estrategia de Cooperación: Supone negociaciones con los actores oponentes al plan para acordar vías comunes de acción, donde éstos terminan cediendo parte de sus intereses en beneficio del resultado esperado, como consecuencia de la acción concertada. Palabra Clave: Negociación.

2. Estrategia de Cooptación: Implica que el actor social que planifica gana la voluntad de otros actores hacia la posición propia, sea por su peso como pivote político, por el peso de su argumentación o por la fuerza de su ideología. Palabra Clave: Apoyo.

3. Estrategia de Conflicto: Es la vía para dirimir el peso relativo de los intereses encontrados, mediante la generación de enfrentamientos focales que amedrenten, desprestigien y agoten al oponente. Palabra Clave: Enfrentamiento.

Cada una de estas estrategias se hacen tangible mediante la definición de acciones concretas procesales o PX'S que pueden variar entre: mesas de diálogo o negociación, referéndum consultivos o revocatorios, reformas constitucionales, cambios en las legislaciones, enfrentamientos públicos y desacreditaciones, entre otras. La elección de la estrategia dependerá del estilo de gerencia pública, la forma como se desenvuelva la dinámica de los actores, los espacios conquistados con los que se cuenten y la intuición de los planificadores.

Tal como se muestra en el Cuadro 5, donde se anexan las estrategias de la construcción de la viabilidad (parte inferior del cuadro), la gamma de proyectos de carácter procesal es versátil y muy amplia. La elección de las estrategias procesales podría variar, incluso una vez seleccionada, en base a cuales de ellas resultan más fáciles de operativizar en el sistema. Los PX'S deberían ser objeto de conformación en forma de Carta Descriptiva, en donde se especifican las operaciones y acciones correspondientes a desarrollar.

En líneas generales, para la implementación del proyecto ENN se seleccionaron las siguientes estrategias de acción de carácter procesal (PX'S):

- PX1: Establecer mesas de diálogo con los actores oponentes para buscar la concertación en las acciones que se realizarán. ESTRATEGIA DE COOPTACIÓN.

- PX2: Convocar a un referéndum consultivo a los venezolanos para medir el nivel de aceptación o rechazo de los programas crediticios implementados por el ejecutivo nacional. ESTRATEGIA DE COOPTACIÓN

- PX3: Establecer alianzas estratégicas con los actuales organismos que agrupan las PYMES para repotenciar y replantear su razón de ser e infraestructura, a cambio del apoyo para el desarrollo del proyecto ENN. ESTRATEGIA DE COOPERACIÓN.

Todas estas estrategias podrían ser utilizadas tanto por los oponentes, como por los diferentes actores que intervienen en el acontecer social. Las con- 
quistas de los espacios direccionales de los diferentes actores están en función de las capacidades y habilidades que tengan éstos en apuntalar hacia una acción procesal selectiva y ajustada al condicionamiento del contexto y al juego político de los diferentes sectores.

\section{Conclusiones}

A través de la presente investigación donde se aplicó el Modelo de Planificación Estratégica Situacional en el ámbito económico - político y social venezolano, se pudo conocer que según estudios exploratorios fundamentados en mesas de trabajo con profesionales, obreros, trabajadores del gobierno, estudiantes, amas de casa y, en fin, representantes de la sociedad civil y del gobierno, el problema que más impacto tiene dentro de la sociedad es el desempleo.

Por su parte, la aplicación de la metodología PES, que integra análisis e intuición, experticia o conocimiento empírico y sistematización conceptual en el manejo de los instrumentos característicos del modelo representado por instancias o momentos, establecieron que la aplicación de proyectos de fomento y apoyo a emprendedores emergentes de negocios es una estrategia de cambio direccional que afecta positivamente los nudos explicativos del problema del desempleo, generando un efecto movilizador efectivo en el vector descriptor de ese problema.

En tal sentido, se recomienda la aplicación de ese proyecto, sin embargo, el sector gobierno no debe obviar los in- tereses contrapuestos de otros actores que podrían estar diametralmente distante a las acciones direccionales gubernamentales. A tal efecto, se hace imperioso desarrollar esas otras estrategias de carácter procesal que factibilicen la posibilidad de aplicar exitosamente el citado proyecto.

Estas acciones procesales podrían ser muy versátiles, pero se exhorta el implementar mesas de concertación y negociación, para así lograr alianzas estratégicas con los sectores adversos al proyecto bolivariano para generar el clima político apropiado que favorezca la adecuada aplicación del proyecto EEN (estrategias de cooptación y cooperación).

Por último, respecto al modelo utilizado como instrumento metodológico de la presente investigación, la planificación de situaciones es un proceso complejo, requiere de la experticia, los conocimientos formarles del arte de dirigir, de intuición, mucho análisis y de un basamento metodológico que guíe. Sin embargo, la práctica del proceso va mucho más allá.

Si bien es cierto que aquí no se aborda el momento que agrupa al resto, como lo es el táctico - operacional (M4) o aquel que precede y preside la acción concertada, tal como lo decía su precursor Carlos Matus (1972): "Planificar es remar contra la corriente iluminados por un faro que nos da fe. Pero después de todo somos ciegos, sordos y la realidad juega con nosotros sin que podamos, por ahora, entender la TOTALIDAD del juego'... 
Planificación situacional aplicada al sector socioeconómico venezolano Alizo, María Alexandra; Graterol, Angela; Añez, Silenis y Ríos, Marisela

\section{Referencias Bibliográficas}

Asamblea Nacional Constituyente (1999). Constitución de la República de Venezuela. (Disponible en: http://www. analitica.com/bitblioteca/).

MPD, Ministerio de Planificación y Desarrollo. Programa Económico 2001. (Disponible en: http://www.mpd.gov.ve/proggob/ind_docofi2.htm)

Corredor, Julio (1997). La Planificación. Enfoques y proposiciones para su aplicación. VADELL. 3ra Edición. Venezuela.

Matus, Carlos (1987). Política, Planificación y Gobierno. Fundación ALTADIR con patrocinio del ILPES y la OPS. 1ra Edición. Venezuela.
Matus, Carlos (1988). Los Tres Cinturones del Gobierno. Fondo Editorial ALTADIR. Venezuela.

Matus, Carlos (1972). Estrategia y Plan. Fondo de Cultura Económica. 1ra Edición. Chile, 1972.

Matus, Carlos (1975). Planificación de Situaciones. Siglo XXI. 1ra Edición.

Matus, Carlos (1997). El Líder sin Estado Mayor. ALTADIR. 1ra Edición. Bolivia.

Matus, Carlos (1998). Adiós Señor Presidente. Ediciones LOM. 1ra Edición. Chile, Junio.

OCEI, Oficina Central de Estadísticas e Información (2001). Anuario Estadístico de Venezuela 2000. División de Publicaciones y Artes Gráficos de la OCEI. 